\title{
ILCEA
}

Revue de l'Institut des langues et cultures

d'Europe, Amérique, Afrique, Asie et Australie

26 | 2016

Mémoire, vérité et justice en Uruguay

\section{¿Justicia o impunidad? Cuentas pendientes a treinta años del retorno a la democracia}

Justice or Impunity? Unresolved Matters Thirty Years after Democratic

Transition in Uruguay

Justice ou impunité? Questions non résolues à trente ans du retour à la démocratie

\section{Francesca Lessa}

\section{OpenEdition}

\section{Journals}

Edición electrónica

URL: http://journals.openedition.org/ilcea/3874

DOI: 10.4000/ilcea.3874

ISSN: 2101-0609

Editor

UGA Éditions/Université Grenoble Alpes

Edición impresa

ISBN: 978-2-84310-334-6

ISSN: 1639-6073

Referencia electrónica

Francesca Lessa, « ¿Justicia o impunidad? Cuentas pendientes a treinta años del retorno a la democracia », ILCEA [En línea], 26 | 2016, Publicado el 07 julio 2016, consultado el 01 mayo 2019. URL : http://journals.openedition.org/ilcea/3874 ; DOI : 10.4000/ilcea.3874

Este documento fue generado automáticamente el 1 mayo 2019.

(C) ILCEA 


\title{
¿Justicia o impunidad? Cuentas pendientes a treinta años del retorno a la democracia
}

\author{
Justice or Impunity? Unresolved Matters Thirty Years after Democratic \\ Transition in Uruguay \\ Justice ou impunité? Questions non résolues à trente ans du retour à la \\ démocratie
}

Francesca Lessa

el día o la noche en que el olvido estalle

salte en pedazos o crepite/

los recuerdos atroces y los de maravilla

quebrarán los barrotes de fuego arrastrarán por fin la verdad por el mundo

y esa verdad será que no hay olvido. Mario BENEDETTI, «Ese gran simulacro» (fragmento).

1 La conmemoración de 30 años del retorno a la democracia el 1 de marzo de 1985 nos ofrece una excelente oportunidad para reflexionar y hacer un balance sobre tres décadas de lucha por verdad y justicia en el Uruguay.

En 2013 y 2014, Uruguay ha ganado elogios internacionales y adquirido la imagen de un bastión del progreso en las Américas. En octubre de 2012, el aborto fue legalizado; más tarde, en 2013, se aprobó el matrimonio igualitario, que reconoce como legítimo el matrimonio civil entre personas del mismo sexo, y además se legalizó la marihuana, colocando de esta forma a Uruguay a la vanguardia de la llamada "guerra contra las drogas» (Lessa \& Le Goff, 2013). Y finalmente, su presidente José «Pepe» Mujica -con su forma campechana, práctica de liderazgo e imagen del «presidente más pobre del mundo»-, constituye un contraste refrescante con la mayoría de los líderes del mundo y 
ha ganado muchos titulares de prestigiosos periódicos internacionales como el The Guardian y el The New York Times.

3 A raíz de estos logros, el 21 de diciembre de 2013, Uruguay fue elegido «país del año» por la famosa revista británica The Economist. Al otorgarle el galardón, la publicación afirmó que dichas reformas no benefician solamente a una nación, sino que, de ser emuladas, podrían favorecer al mundo entero.

Yuxtaponiendo estos logros recientes en el campo de los derechos humanos con la cuestión de los crímenes de la dictadura en Uruguay, la disparidad no podría ser más clara y paradójica. Eso es a tal punto que, en realidad, parece que se estuviera hablando de dos países diferentes dado lo marcado de los contrastes entre los avances del presente y las cuentas pendientes del pasado de la dictadura que aún quedan por resolver plenamente.

5 En este artículo enmarcaré mi discusión en términos de lo que se ha logrado en estos 30 años de democracia a la vez que subrayaré las tareas que quedan irresueltas y por tanto el nuevo gobierno que asumió en marzo de 2015 habrá de encargarse.

6 Mi análisis se divide en dos partes. En primer lugar, voy a insertar el caso uruguayo en el marco regional del Cono Sur, comparándolo brevemente con las trayectorias de la lucha por verdad y justicia en Argentina y Chile. En la segunda parte, e inspirada en el informe sobre Uruguay presentado en setiembre de 2014 al Consejo de Derechos Humanos de las Naciones Unidas por el Relator Especial sobre la promoción de la verdad, la justicia, la reparación y las garantías de no repetición, Pablo de Greiff, la discusión se organizará en torno a cuatro ejes principales: justicia, verdad, memoria y reparación.

\section{Luchas contra la impunidad en el Cono Sur. una visión comparativa}

7 Saldar las cuentas con un pasado marcado por violaciones a los derechos humanos como las perpetradas en el Cono Sur en las dictaduras de los 70 y 80, no es tarea sencilla. En efecto, casi 30 años después de la transición democrática en esta región, las cuentas pendientes de la justicia y la impunidad persisten en las sociedades y no hay indicios de que vayan a desvanecerse en el corto plazo.

8 Entre finales de los 60 y de los 80, Argentina, Chile y Uruguay -como también Bolivia, Brasil y Paraguay- fueron víctimas de dictaduras cívico-militares inspiradas por la Doctrina de la Seguridad Nacional en el contexto global de la Guerra Fría. A pesar de las peculiaridades de cada régimen, todos implementaron políticas de represión contra diferentes sectores de la sociedad - desde los grupos armados como los Montoneros argentinos, al MIR chileno y los Tupamaros uruguayos, a los estudiantes, sindicalistas, periodistas, políticos de izquierda y activistas de derechos humanos-, cometiendo graves y sistemáticas violaciones de los derechos humanos, entre ellas desapariciones forzadas, tortura, asesinatos y ejecuciones arbitrarias, abusos sexuales, apropiación de niños, y encarcelamiento prolongado (CONADEP, 2006).

9 Además, en ese entonces fue creada la Operación Cóndor o Plan Cóndor, una red transnacional secreta de operaciones de inteligencia y contrainsurgencia de los regímenes militares de Argentina, Chile, Uruguay, Paraguay, Bolivia y Brasil. Su objeto fue eliminar a opositores políticos en el exilio o refugiados en los países vecinos, 
estableciendo en la práctica una zona de terror sin fronteras a lo largo y ancho de América del Sur (Dinges, 2004; McSherry, 2005).

En los años 80 y 90, con el retorno de la democracia a la región, cada sociedad se enfrentó con análogos desafíos y dilemas políticos, legales y morales relacionados con proporcionar respuestas a las graves violaciones de derechos humanos cometidos bajo las dictaduras. Más allá de las particularidades de las trayectorias individuales, cada país ha sido testigo de éxitos, fracasos, contratiempos y giros inesperados a lo largo de tres décadas. Argentina ha sido en general considerado como "un protagonista global» (Sikkink, 2008) en la lucha por los derechos humanos y en el campo de la justicia transicional (Crenzel, 2008). Entre los numerosos logros, cabe mencionar la investigación sobre las desapariciones forzadas de la Comisión CONADEP (1983-1984) -que fue la primera en completar un informe final y recibir atención internacional-; el juicio a las juntas militares entre 1984 y 1985 -un hecho que marcó una profunda ruptura de la impunidad que había prevalecido hasta entonces en Argentina-, las leyes de reparación de los 90, los juicios por la verdad de finales de los 90, y la anulación de las leyes de impunidad en los 2000. Hasta septiembre de 2015 hubo un total de 147 juicios por delitos de lesa humanidad finalizados desde el 2006, con 622 individuos condenados y 57 absueltos, mientras que otras 2166 personas se encuentran imputadas en este momento por un total de 514 causas $^{1}$.

11 Por otro lado, en Chile, se pueden destacar hechos cardinales como la labor de la Comisión Nacional de Verdad y Reconciliación (1990-1991) que produjo el conocido Informe Rettig sobre graves violaciones a los derechos humanos; la Comisión Nacional sobre Prisión Política y Tortura (2004-2005), la Comisión Asesora para la Calificación de Detenidos Desaparecidos, Ejecutados Políticos y Víctimas de Prisión Política y Tortura, para calificar nuevos casos de víctimas de la dictadura (2010), leyes de reparación en los 90 para los familiares de víctimas de desapariciones forzadas y ejecuciones políticas y en los 2000 otorgando una pensión y otros beneficios para las víctimas de prisión política y tortura (Lira, 2011). Al 1 de diciembre de 2015, el Programa de Derechos Humanos del Ministerio de Interior y Seguridad Pública señalaba que existen 1373 ex agentes procesados, acusados y condenados. De ellos, 495 se encuentran en calidad de procesados, 216 están en calidad de acusados, 180 han sido condenados por sentencia de primera instancia, 138 han sido condenados por sentencia de segunda instancia resuelta por una Corte de Apelaciones, y 344 de ellos han sido condenados por sentencia ejecutoriada dictada por la Corte Suprema ${ }^{2}$. De los 344 ex agentes que han sido alguna vez condenados con una sentencia ejecutoriada dictada por la Sala Penal de la Corte Suprema, 163 de ellos recibieron una condena de presidio efectivo. De ellos, se encuentran cumpliendo presidio efectivo 117 ex agentes. El resto, o ya cumplieron su condena, o fallecieron durante su cumplimiento, o poco antes de entrar a cumplirla. Al 30 de noviembre de 2015, existen 1048 causas vigentes por violaciones a los derechos humanos bajo la pasada dictadura.

12 Por supuesto que, pese a estos importantes resultados, aún persisten -tanto en Argentina como en Chile-, obstáculos y desafíos; entre ellos las demoras y dificultades en la administración de justicia, el trato hacia los testigos, la resistencia de las cortes locales a aplicar el derecho internacional y los impedimentos de leyes de amnistía e impunidad aún vigentes.

13 Este breve análisis comparativo de los países del Cono Sur permite resaltar algunas similitudes y diferencias. Las desparejas trayectorias y dinámicas en la lucha por verdad y justicia en Argentina, Chile y Uruguay se explican en parte a la luz de tres factores 
principales. En primer lugar, las diferentes maneras en las que se dieron los procesos de transición a la democracia: una situación de colapso e implosión de la dictadura argentina frente a las transiciones negociadas entre las fuerzas armadas y los partidos políticos en Chile y Uruguay. Vale la pena mencionar aquí las palabras del ex presidente chileno Patricio Aylwin, quien poco después de la transición consideraba que solo se podía hacer justicia «en la medida de lo posible» (Barahona de Brito, 1997: 176), resaltando de tal manera los obstáculos que Chile enfrentaba todavía a la salida de la dictadura. En segundo lugar, los distintos niveles de voluntad política por parte de los gobiernos democráticos para hacerse cargo del tema, donde se pueden destacar los compromisos y los avances bajo las presidencias de Raúl Alfonsín y Néstor Kirchner en Argentina, de Patricio Aylwin, Ricardo Lagos y Michelle Bachelet en Chile, y de Tabaré Vázquez y José Mujica en Uruguay, a diferencia de las políticas de impunidad de los 80 y 90, especialmente durante los gobiernos de Carlos Menem en Argentina, y de Julio María Sanguinetti y Luis Alberto Lacalle en Uruguay. Finalmente, la falta de reformas de los respectivos poderes judiciales y fuerzas armadas después de la transición ha jugado en contra de la lucha por verdad y justicia, demorando en muchas oportunidades los intentos de avanzar en la investigación de las atrocidades de las dictaduras.

14 Considerando las similitudes, es importante recordar que en los tres países la lucha por verdad y justicia ha sido llevada a cabo, en gran medida, gracias a los esfuerzos perseverantes de actores de la sociedad civil -especialmente sobrevivientes, familiares de las víctimas, activistas y abogados de derechos humanos-, como también por algunos jueces y fiscales (Juan Guzmán en Chile, Mariana Mota y Mirtha Guianze en Uruguay) que impulsaron y se movilizaron a lo largo de tres décadas para aclarar los crímenes cometidos y sancionar a los responsables, en un contexto en el que los Estados impulsaban comúnmente políticas de impunidad y silencio. En palabras sobre Uruguay del Relator Especial Pablo de Greiff, «fueron las víctimas, sus familiares y las asociaciones quienes impulsaron, y siguen impulsando, sin descanso y con un compromiso admirable, las iniciativas en favor de la verdad, la justicia, la reparación y las garantías de no repetición» (2014: párrafo 6, página 6).

Un aspecto a enfatizar es que mientras que en Argentina y Chile la lucha por verdad y justicia ha estado mayoritariamente en manos de los grupos de víctimas y de activistas de derechos humanos, en Uruguay los actores involucrados son mucho más amplios y heterogéneos, incluyendo por supuesto a los afectados y militantes de derechos humanos, pero también al movimiento sindical, a la federación de estudiantes e incluso a las organizaciones barriales.

La bandera de la lucha contra la impunidad en los tres países en muchas ocasiones coincidió con la lucha contra las leyes de impunidad -sancionadas bajo las mismas dictaduras o después en democracia- que impedían las investigaciones de los crímenes cometidos. Argentina, Chile y Uruguay recibieron condenas tanto por parte de la Comisión Interamericana de Derechos Humanos (CIDH) como de la Corte Interamericana (Corte IDH), debido a la vigencia de dichas leyes. Argentina y Uruguay fueron sancionados por la CIDH ya en 1992 (CIDH, 1992; IACHR, 1992), mientras que Chile y Uruguay fueron condenados también por la Corte IDH en 2006 en el caso Almonacid Arellano vs. Chile y en 2011 en el caso Gelman vs. Uruguay. En ambas sentencias, la Corte IDH dispuso que las leyes de amnistía no pueden representar un obstáculo para la investigación, juzgamiento $\mathrm{y}$, en su caso, sanción de los responsables de los casos implicados en las causas como también de otras violaciones similares acontecidas en Chile y Uruguay (IACtHR, 2011). 
Finalmente, los tres países se encuentran en una «carrera contra el tiempo» para impedir que los perpetradores de violaciones a los derechos humanos mueran sin ser castigados. Los tres Estados deben brindar respuestas en términos de justicia, verdad y reparación a las víctimas, sus familiares, y las sociedades en general, antes que sea demasiado tarde. Como recalca nuevamente el Relator Especial sobre Uruguay -pero con aplicación también en los otros dos países- «la falta de avances [...] y el transcurso del tiempo -ya casi 30 años desde el final de la dictadura- han generado un enorme desgaste en las víctimas y sus familiares. Considerando la avanzada edad de muchas de ellas, es urgente que sus reclamos sean atendidos» (de Greiff, 2014: párrafo 6, página 6).

\section{Cuentas pendientes a treinta años de la transición en Uruguay}

Por mucho tiempo la lucha contra la impunidad por los crímenes de la dictadura en Uruguay fue sinónimo de la lucha contra la Ley de Caducidad (Burt, Fried \& Lessa, 2013; Marchesi, 2013; Fried \& Lessa, 2011). De hecho, dicha ley definió la trayectoria de la justicia transicional en Uruguay, constituyendo un «obstáculo real y también simbólico a los avances en la búsqueda de verdad y justicia» (Lessa, 2014: 91).

En esta segunda parte del artículo, realizo un análisis y un balance de los éxitos de los últimos treinta años en las áreas de justicia, verdad, memoria y reparación y al mismo tiempo marco los retos pendientes para el nuevo gobierno que se instaló a comienzo de 2015.

19 Aun cuando la Ley de Caducidad ha sido el eje fundamental de la lucha por verdad y justicia en Uruguay, en los últimos años -especialmente desde su revocación en 2011- se puso en evidencia que la lucha contra la impunidad debe ir mucho más allá de dicha ley. Efectivamente, existen muchos otros obstáculos en el camino a la justicia que necesitan ser abordados y superados. Como muchos defensores de derechos humanos -incluyendo el abogado Pablo Chargoñia y el periodista Roger Rodríguez- han manifestado en varias oportunidades, la impunidad en Uruguay va más allá de leyes específicas y se ha transformado en una «impunidad fáctica» $\mathrm{y}$ «una cultura de impunidad».

\section{Justicia}

El campo de la justicia ha sido el más perjudicado por la sanción de la Ley de Caducidad. Por casi 16 años -entre diciembre de 1986 y octubre de 2002- la «ley de impunidad» logró cerrar cualquier intento de investigar los delitos de la dictadura. Como bien lo analizó Roger Rodríguez, todas las causas de desaparición forzada fueron cerradas por el presidente Julio María Sanguinetti, quien también impidió la investigación judicial de diez de dieciséis muertes, mientras que otras cuatro las amparó Luis Alberto Lacalle, una Enrique Tarigo y otra Tabaré Vázquez (Rodríguez, 2011). Es decir que cuatro de los cinco gobiernos democráticos desde la transición, aplicaron por lo menos una vez la Ley de Caducidad para obstruir los intentos de lograr justicia. Más allá de las políticas de impunidad de los gobiernos y del Poder Ejecutivo en particular, el Poder Judicial tampoco fue impulsor de justicia por estos crímenes. La naturaleza conservadora de la judicatura, junto con el sistema de promoción y evaluación de los jueces así como la falta de reformas, permitieron la consolidación de la impunidad. Durante las décadas de los 80 
y 90 solo algunos jueces y fiscales se atrevieron a desafiar la estructura de impunidad consagrada en la Ley de Caducidad. Quienes lo hicieron, como Alberto Reyes, Estela Jubette, Alejando Recarey y Mirtha Guianze, además pagaron un alto precio personal y profesional, sufriendo campañas de desprestigio y corriendo el riesgo de ser sancionados y/o trasladados a otras dependencias judiciales. El caso más reciente fue el traslado de la jueza Mariana Mota en febrero de 2013 a un fuero civil. Pese a esta situación, muchos sectores de la sociedad no se rindieron y siguieron luchando incasablemente: sus esfuerzos fueron finalmente exitosos.

21 La primera pequeña brecha a la Ley de Caducidad ocurrió en mayo de 2000, cuando la jueza civil Estela Jubette respaldó la petición de Tota Quinteros, y ordenó al Poder Ejecutivo llevar a cabo una investigación administrativa sobre la desaparición de su hija Elena. La investigación ordenada por Jubette no produjo hallazgos significativos, por lo que en noviembre de 2000 Tota Quinteros y su abogado Pablo Chargoñia solicitaron la reapertura de la investigación penal del caso, argumentando que la Ley de Caducidad no era aplicable a los civiles. En octubre de 2002, el juez Eduardo Cavalli aceptó la tesis de Chargoñia y el primer procesamiento por crímenes de la dictadura tuvo lugar contra el ex canciller de la dictadura Juan Carlos Blanco, imputado por el encarcelamiento ilegal y desaparición de Elena Quinteros.

El primer gobierno del Frente Amplio, con la presidencia de Tabaré Vázquez en 2005, aplicó una interpretación diferente de la Ley de Caducidad que permitió la apertura de procedimientos judiciales en aproximadamente 25 casos que afectaban a cerca de 60 víctimas. En el posterior gobierno del Frente Amplio, José Mujica continuó esta tendencia, facultando a los jueces para investigar libremente los casos presentados. A la luz de estos avances Uruguay procesó a dos de sus dictadores: condenó a 30 años de prisión al ex presidente civil Juan María Bordaberry en febrero de 2010 por orquestar dos asesinatos políticos y nueve desapariciones y por encabezar el golpe de Estado de 1973. En 2009 condenó al General (R) Gregorio Álvarez a 25 años de prisión por 37 asesinatos de uruguayos secuestrados en Argentina. Finalmente, el ex Canciller Juan Carlos Blanco fue condenado en 2010 a 20 años de prisión en el caso Elena Quinteros y seis oficiales militares y dos policías (entre ellos José Gavazzo, Jorge Silveira y Gilberto Vázquez) fueron procesados y sentenciados en 2009 por 28 desapariciones de uruguayos en Buenos Aires en 1976. Finalmente, en mayo de 2013 se produjo la primera condena de un oficial militar en actividad, el General Miguel Dalmao, por el asesinato de Nibia Sabalsagaray caso en el que en octubre de 2009, la Suprema Corte de Justicia había declarado por primera vez la inconstitucionalidad de la Ley de Caducidad, a pedido de la Fiscal Mirtha Guianze.

El año 2011 fue clave en la lucha contra la impunidad. En febrero, la Corte IDH condenó por primera vez a Uruguay en el caso Gelman, sentenciando que la Ley de Caducidad no era válida debido a su incompatibilidad con la Convención Americana de Derechos Humanos y con la Convención Interamericana sobre Desaparición Forzada de Personas, por obstruir la investigación y eventual sanción de los responsables de graves violaciones a los derechos humanos, en ese caso y en todos los otros casos similares que se habían producido en Uruguay. Utilizando estratégicamente dicho fallo, los defensores de derechos humanos redoblaron la presión y exigencia de eliminar la Ley de Caducidad del sistema jurídico, también tomando en cuenta la posible prescripción de los delitos de la dictadura en noviembre de 2011. 
24 En junio, debido a la presión de familiares de las víctimas de la dictadura y de la agrupación HIJOS, el Poder Ejecutivo promulgó la Resolución 323, que reabrió 88 casos de derechos humanos que habían sido archivados por la aplicación de la «ley de impunidad» y encargaba al Poder Judicial determinar, caso por caso, si las causas debían reabrirse.

Paralelamente, la sociedad civil trabajó activamente para presentar nuevas denuncias penales antes del $1^{\circ}$ de noviembre. La Federación de Estudiantes Universitarios del Uruguay (FEUU), junto con la agrupación Iguales y Punto y el abogado Federico Álvarez Petraglia, promovieron junto con víctimas y activistas, la presentación de nuevos casos. Se produjo un total de 170 nuevas denuncias de tortura, detención ilegal y secuestro. Al mismo tiempo, numerosos ex-presos políticos presentaron denuncias por tortura; entre ellas, por los abusos sufridos en el centro clandestino de detención conocido como «300 Carlos» y la formulada por un grupo de ex-presas políticas por torturas a 112 hombres y mujeres, responsabilizando a militares, policías, enfermeras y médicos y haciendo hincapié en la violencia sexual (Contreras \& Touriño, 2011). Estas importantes y nuevas denuncias pusieron el centro de atención sobre la tortura, allanando el camino para que por primera vez se iniciaran juicios específicamente por el delito de tortura, incluyendo también por vez primera la violencia sexual como una de sus modalidades más graves.

Finalmente, tras la fallida «ley interpretativa» en mayo de 2011, a finales de octubre de 2011 - dos años después del fracaso del plebiscito de la papeleta rosada- el gobierno sancionó la Ley n. ${ }^{\circ} 18.831$ que reestableció la pretensión punitiva del Estado por los crímenes de la dictadura. Sin embargo, poco tiempo después, en febrero de 2013, la Suprema Corte de Justicia -mientras que confirmó la constitucionalidad del artículo $1^{\circ}$ de la ley que restablece el pleno ejercicio de la pretensión punitiva del Estado en relación a estos delitos- argumentó que los artículos $2^{\circ}$ y $3^{\circ}$ que establecen la imprescriptibilidad de los delitos cometidos en aplicación del terrorismo de Estado y los define como crímenes de lesa humanidad, eran «contrarios a la Constitución por violar el principio de legalidad en materia penal y de no retroactividad de la ley penal más gravosa» (de Greiff, 2014: párrafo 18, p. 9). El fallo de la Corte - publicado unos días después del traslado de la Jueza Mariana Mota- fue recibido por una ola de condenas nacionales e internacionales, incluyendo a la ONU, la CIDH, la Corte IDH y la Institución Nacional de Derechos Humanos de Uruguay. Navi Pillay, la Alta Comisionada de las Naciones Unidas para los Derechos Humanos en ese entonces, recalcó que la sentencia «puede reestablecer las sombras de la impunidad» en el país.

Es importante resaltar que varios fiscales y jueces de primera y segunda instancia, se han distanciado de la jurisprudencia de la Corte y han decidido continuar con las causas. No obstante, este retroceso junto con el traslado de Mota, significó que en 2013 solo cuatro causas llegaron a sentencia. A comienzos de 2014, los casos que llevaba Mota se encontraban en una situación de "semiparálisis»" y las defensas de los imputados han logrado «dilatorias en cada uno de los expedientes, lo cual constituye el mayor freno» ${ }^{4}$ a la justicia. Utilizando información brindada por el Observatorio Luz Ibarburu (OLI) sobre el estatus de las causas penales en Uruguay, se registran 271 causas abiertas, de las que 71 han sido archivadas, 6 tienen sentencia firme, 9 están en la etapa de sumario mientras que la gran mayoría en la etapa de presumario, 163 causas $^{5}$. Siempre según datos del OLI, desde el año 2002 fueron procesadas 26 personas por crímenes de la dictadura. En 4 casos se revocó el procesamiento o se absolvió al procesado. Considerando tales revocaciones y los casos de procesados o condenados fallecidos, la situación a julio de 2015 es la de un 
total de 18 imputados (procesados o condenados) ${ }^{6}$. A nivel de la justicia, por lo tanto, se registra un número muy bajo de juicios que fueron finalizados como también muy pocas personas que han tenido que responder por los crímenes del terrorismo de Estado. Además, como ha subrayado recientemente el coordinador ejecutivo del OLI, Raúl Olivera, a pesar de que una de las características principales de la represión en Uruguay fue la aplicación sistemática de torturas, no hubo hasta la fecha ni un procesamiento por el delito de tortura, como tampoco por delitos sexuales ${ }^{7}$, a pesar de que tales crímenes ya fueron denunciados, tanto por hombres como mujeres, hace años en 2010 y 2011 respectivamente. El panorama de la justicia no resulta muy alentador especialmente si consideramos que ya pasaron más de 40 años de la dictadura y las demoras injustificadas que los sobrevivientes y sus familiares tuvieron que padecer en su búsqueda de verdad y justicia.

Los principales retos a enfrentar en el camino a la justicia, incluyen la demoras indebidas e injustificadas al avance de los procesos, el limitado acceso a los archivos oficiales para incorporar la información necesaria a los expedientes, el hecho que el $75 \%$ de las causas penales carecen de abogados que hagan un seguimiento apropiado, y la falta de conocimiento y aplicación del Derecho Internacional de los Derechos Humanos por parte de los jueces. Subrayando algunos cambios importantes que se han dado en los últimos meses, es importante resaltar por lo menos dos hechos claves. En primer lugar, la Suprema Corte de Justicia ha empezado a alejarse de su misma jurisprudencia de 2013, cuando consideró en muchos casos que los crímenes de la dictadura no eran crímenes de lesa humanidad y por lo tanto podían estar sujetos a la prescripción de la acción penal. En dos sentencias, de septiembre de 2014 y agosto de 2015, la Corte empezó a adoptar la postura, reconocida y aceptada ya a nivel internacional y regional, que dichos crímenes constituyen crímenes de lesa humanidad ${ }^{8}$. Por otro lado, en septiembre de 2015, el Fiscal de Corte, Jorge Díaz, creó por resolución una Unidad Especializada en Derechos Humanos para que asesore a la Fiscalía General de la Nación en la investigación de los crímenes cometidos durante la última dictadura (1973-1985) ${ }^{9}$. La unidad está integrada por el Fiscal Adjunto de Corte, Ariel Cancela y por las fiscales penales María de los Ángeles Camiño, Ana María Tellechea y Stella Llorente, y la Fiscal Adscripta María Carolina Rico. El objetivo de la iniciativa es desarrollar una estrategia común a nivel de la Fiscalía en la persecución penal de los crímenes de la dictadura. La creación de esta unidad es un avance muy importante y que permitirá abordar los crímenes del terrorismo de Estado de una forma más global, como parte de un plan criminal sistemático de delitos, y no como crímenes aislados.

\section{Verdad}

La búsqueda de la verdad, como los otros campos, ha sido caracterizada por la misma paradoja: por un lado la ausencia del Estado, que fue verdugo de sus propios ciudadanos y por lo tanto directamente responsable según el Derecho Internacional de los Derechos Humanos de investigar los crímenes y sancionar a los culpables y, por el otro lado, los esfuerzos de la sociedad para brindar respuestas sobre los delitos del pasado, llenando el vacío dejado por el Estado. A la salida de la dictadura, gracias a la labor de los partidos de oposición (Frente Amplio y Partido Nacional), se instalaron en el Parlamento cuatro comisiones investigadoras para aclarar los casos de desapariciones y de algunos crímenes puntuales (como los asesinatos de los legisladores Zelmar Michelini y Héctor Gutiérrez Ruiz, la desaparición de Elena Quinteros y el papel del ex Canciller, así como la muerte 
por envenenamiento de Cecilia Fontana de Heber). A pesar de los limitados recursos y competencias, dichas comisiones recopilaron información y testimonios. Ya era evidente en ese momento la postura hacia la impunidad del gobierno de Sanguinetti, quien descalificó las conclusiones de las comisiones y nunca respondió a los informes finales. En esa situación de ausencia y desinterés del gobierno en la búsqueda de la verdad, la organización social Servicio Paz y Justicia, SERPAJ, publicó en marzo de 1989 su investigación sobre las violaciones de derechos humanos cometidas entre 1972 y 1985, titulada Uruguay: Nunca Más. El informe estudia la represión llevada a cabo por la dictadura, considerando la tortura, el encarcelamiento prolongado, las desapariciones forzadas, la coordinación regional de la represión y también las consecuencias más profundas del terrorismo de Estado y su impacto en la sociedad. Durante casi dos décadas, el informe de SERPAJ fue el único documento que proporcionaba una visión completa sobre la represión, recogiendo testimonios de las víctimas y preservándolos para el futuro ${ }^{10}$.

La fórmula «ni verdad ni justicia» adoptada por el gobierno de transición uruguayo, persistió como política de Estado durante 15 años. Hasta el establecimiento de la Comisión para la Paz en agosto de 2000, no hubo ninguna investigación oficial sobre las graves violaciones de derechos humanos; de hecho, no hubo ningún reconocimiento por parte del Estado uruguayo de que esos crímenes habían sido cometidos (Burt, Fried \& Lessa, 2013: 8). El gobierno de Jorge Batlle reconoció, por primera vez y oficialmente, la responsabilidad del Estado en los crímenes de la dictadura, con la Comisión para la Paz (COMIPAZ). Pese a este importante reconocimiento, las tareas de la COMIPAZ fueron restringidas a la investigación de las desapariciones forzadas y se le otorgaron poderes y recursos muy limitados. Además, la COMIPAZ transmitió información que más tarde resultó ser falsa, cuando a partir de 2005 se encontraron por primera vez los restos de detenidos desaparecidos enterrados en suelo uruguayo. También, dicha Comisión afirmó que Simón Riquelo, el hijo de Sara Méndez, había muerto en Argentina, pero fue encontrado con vida en 2002 (Burt, Fried \& Lessa, 2013: 13). En ese contexto, poco tiempo después de que cerraran los trabajos de la Comisión en 2003, se publicó el informe A todos ellos. Informe de Madres y Familiares de Uruguayos Detenidos Desaparecidos, en 2004 -una valiente iniciativa nuevamente de la sociedad civil que recopila información sobre el destino de los detenidos desaparecidos.

Bajo los gobiernos del Frente Amplio, de 2005 en adelante, se llevaron a cabo investigaciones que tuvieron importantes resultados, por parte de arqueólogos forenses e historiadores de la Universidad de la República. En 2007 se publicó la Investigación histórica sobre detenidos desaparecidos, y en 2008 la Investigación histórica sobre la dictadura y el terrorismo de Estado en Uruguay (1973-1985). La última actualización de la investigación, de octubre 2014, identificó un total de 218 casos de detenidos-desaparecidos, 3 de los cuales se refieren a niños ${ }^{11}$. Gracias a las excavaciones de los arqueólogos, se pudo finalmente encontrar y localizar los restos de cuatros detenidos-desaparecidos: en 2005, los de Ubagesner Chaves Sosa y de Fernando Miranda, en 2011 los del maestro Julio Castro, y en 2012 los de Ricardo Blanco Valiente.

Los principales retos irresueltos en el área de la verdad se refieren a proteger los archivos y garantizar el acceso a la documentación para las víctimas, sus familiares y su incorporación en las causas judiciales. Al mismo tiempo, hay que resaltar que la búsqueda de la verdad se ha enfocado generalmente hacia los casos de desaparición forzada, dejando a un lado en varias oportunidades a las víctimas de prisión prolongada y tortura. 
Es necesario considerar un universo más amplio de víctimas, que incluya a los desaparecidos y al mismo tiempo a las víctimas de detención y tortura y de las otras manifestaciones represivas que tuvieron lugar durante la dictadura. Al asumir por un segundo gobierno, el Presidente Tabaré Vázquez anunció en mayo de 2015 la creación del Grupo de Trabajo por Verdad y Justicia (GTVyJ), cuyo cometido esencial es la investigación de los crímenes cometidos en el marco de la dictadura. El GTVyJ está integrado por Macarena Gelman, Felipe Michelini, Emilia Carlevaro, Susana Andrade, Pedro Sclofsky, Ademar Olivera y Mario Cayota. La Dirección de la Secretaría de Derechos Humanos para el Pasado Reciente la ocupará Isabel Wschevor. Tiene a su cargo varias tareas, entre ellas profundizar el análisis de los archivos existentes y la búsqueda de información relevante en la materia, organizar el registro de testimonios de víctimas o familiares sobre delitos de lesa humanidad, seguir el cumplimiento de las sentencias dictadas contra el Estado tanto a nivel nacional como internacional y abordar otras acciones conducentes al objetivo planteado ${ }^{12}$. A pesar de que ya pasaron más de seis meses desde su creación, aun no sido explicitado o difundido el plan de trabajo de esta nueva institución.

\section{Memoria}

Bajo este rubro también es necesario resaltar cómo la gran mayoría de iniciativas de memoria han sido lideradas y llevadas a cabo por los activistas de derechos humanos, victimas, familiares y los sindicatos. El Estado está, otra vez, notablemente ausente. El principal ejemplo es el del Memorial de los Detenidos Desaparecidos inaugurado en 2001 en el Parque Vaz Ferreira del Cerro de Montevideo, cuya construcción fue promovida la agrupación de Madres y Familiares de Uruguayos Detenidos Desaparecidos, una Comisión Nacional integrada por 33 ciudadanos y que contó con el auspicio de la Intendencia y la Junta Departamental de Montevideo y la Sociedad de Arquitectos del Uruguay, cuya financiación fue a través de donaciones. El único acto con la presencia del Estado ocurrió en marzo de 2012, en ocasión de un acto público en la sala de la Asamblea General del Parlamento, en el que el Presidente de la República, en cumplimiento de la sentencia de la Corte IDH, reconoció la responsabilidad institucional del Estado uruguayo en los hechos de violación de los derechos humanos de María Claudia García Iruretagoyena de Gelman, su hija María Macarena Gelman Iruretagoyena y de Juan Gelman. En el marco del mismo acto, se cedió el edificio ocupado por el Centro de Altos Estudios Estratégicos (CALEN) como la nueva sede de la Institución Nacional de Derechos Humanos y Defensoría del Pueblo. Otras iniciativas, como el Museo de la Memoria (inaugurado en 2007) y el proyecto más reciente Marcas de la Memoria para instalar 29 placas en lugares públicos significativos de la resistencia a la dictadura, han sido otra vez impulsadas por organizaciones sociales, de derechos humanos, sindicales y la Universidad.

\section{Reparación}

La adopción de medidas reparatorias de las violaciones de derechos humanos se remonta a los primeros días de marzo de 1985, cuando el gobierno del Presidente Sanguinetti adoptó disposiciones para facilitar el retorno y la reintegración social de los exiliados y para restituir los empleos públicos a las personas injustamente despedidas durante la dictadura ${ }^{13}$. Sin embargo, leyes de reparación para las víctimas de graves crímenes y sus 
familiares demoraron veinte años y no se sancionaron hasta la instalación del gobierno del Presidente Vázquez.

En setiembre de 2005 se creó la categoría legal de "ausente debido a la desaparición forzada» para las personas desaparecidas en Uruguay y en el exterior. En octubre de 2006, gracias a las presiones y el trabajo llevado a cabo por CRYSOL (Asociación de ex presos y presas políticos/as del Uruguay), la Ley $n .{ }^{\circ} 18.033$ restituyó los derechos jubilatorios a las personas que por motivos políticos o sindicales no habían podido trabajar entre febrero de 1973 y 1985, otorgando también una pensión especial reparatoria a las personas detenidas y procesadas durante la dictadura. Finalmente, en setiembre de 2009, el Estado reconoció las prácticas sistemáticas de represión, tortura, desapariciones y homicidios, y se creó una comisión especial para indemnizar a las víctimas, incluidos los presos políticos, los menores nacidos en cautiverio o desaparecidos, y las víctimas de tortura.

A pesar de estos avances, y como subraya el Relator Especial Pablo de Greiff, a junio de 2014, sólo se habrían expedido 360 expedientes con reparación económica a través de esta última ley. Además, estas medidas distan de conformarse con la noción de reparación integral para las víctimas. En particular, estas leyes padecen de una confusión entre diferentes conjuntos de derechos, es decir los derechos que corresponden a las víctimas de violaciones a los derechos humanos y los derechos laborales y jubilatorios, que «tienen una naturaleza y fundamento distinto» (de Greiff, 2014: párrafo 44, página 16). Dichas leyes obligan a las víctimas a tener que elegir entre estos diversos derechos de pensión y de reparación. Al mismo tiempo, las leyes no abarcan a todas las categorías relevantes de las víctimas y muchos beneficiarios han quedado por lo tanto excluidos.

\section{Reflexiones finales}

37 Este artículo ha intentado proporcionar una discusión alrededor de algunos de los logros en la lucha contra la impunidad en estos últimos 30 años, como también subrayar algunas de las cuentas pendientes que resulta necesario resolver a la brevedad. Como bien lo acentúa Pablo de Greiff al final de su reporte, la necesidad de responder a los delitos de la dictadura no significa «[...] revanchismo ni mirar sólo el pasado, sino crear bases sólidas para una sociedad justa, equitativa, que permita a las nuevas generaciones abordar los retos del futuro» (2014: párrafo 74, página 24). Los 40 años que pasaron desde que se cometieron los crímenes, implican que sea absolutamente urgente que el Estado uruguayo actúe sin más demoras en proporcionar respuestas ya largamente esperadas, a los familiares de las víctimas, los sobrevivientes y la sociedad en general, sobre los crímenes que se cometieron durante la dictadura.

Uruguay ratificó el Pacto Internacional de Derechos Civiles y Políticos en abril de 1970; según el artículo 2(1) de dicho Pacto, cada Estado se compromete «[...] a respetar y a garantizar a todos los individuos que se encuentren en su territorio y estén sujetos a su jurisdicción los derechos reconocidos en el presente Pacto, sin distinción alguna [...]». Además, el artículo 2(3a) recalca cómo cada Estado se compromete a garantizar que «Toda persona cuyos derechos o libertades hayan sido violados podrá interponer un recurso efectivo, aun cuando tal violación hubiera sido cometida por personas que actuaban en ejercicio de sus funciones oficiales» ${ }^{14}$. Por lo tanto, en la opinión de la autora, el Estado uruguayo no solamente es responsable por la comisión de los crímenes de la dictadura sino también por la falta investigación y sanción a los responsables durante la 
democracia. En la jurisprudencia de la Corte IDH ha sido reconocido repetidamente que «la privación continua de la verdad acerca del destino de un desaparecido constituye una forma de trato cruel e inhumano para los familiares cercanos $»^{15}$. La Corte ha afirmado además que el Estado tiene la obligación de «garantizar el derecho a la integridad personal de los familiares también por la vía de investigaciones efectivas» y que «la ausencia de recursos efectivos ha sido considerada por la Corte como fuente de sufrimiento y angustia adicionales para las víctimas y sus familiares» ${ }^{16}$.

Si bien es fundamental resaltar los avances que se lograron en estos 30 años, -entre ellos la localización de los niños/as desaparecidos/as, como Macarena Gelman- algunas sentencias contra líderes emblemáticos de la dictadura -como el dictador Bordaberry, y la identificación de los restos de algunos detenidos desaparecidos-, mucho queda aún por hacer. En Uruguay, fueron las víctimas, sus familiares, y activistas de la sociedad civil quienes se han hecho cargo de investigar los delitos y aportar información y documentación a la justicia. Esta es una tarea que corresponde al Estado uruguayo el que, hasta ahora, se ha quedado atrás en el cumplimiento de sus obligaciones en el marco del Derecho Internacional de los Derechos Humanos, que asumió soberana y voluntariamente al ratificar los convenios en dicha materia.

Concluyendo el informe relativo a su misión en Uruguay en 2013, el Relator Especial de la ONU Pablo de Greiff formuló conclusiones y recomendaciones necesarias para cumplir adecuadamente con las tareas inconclusas del pasado reciente (de Greiff, 2014: 21-27). Las recomendaciones más urgentes en las que el nuevo gobierno debiera trabajar en la opinión de esta autora, abarcan entre otras: remover todos los obstáculos que bloquean el progreso de las causas y acciones judiciales para que puedan avanzar sin demoras injustificadas; y diseñar e implementar políticas públicas de reparación integral para las víctimas, con reparaciones simbólicas y materiales, y que sean dirigidas a las diferentes categorías de víctimas; la reparación además comprende el derecho a la verdad que, como dijo la CIDH, abarca a las víctimas y sus familiares pero también a toda la sociedad, que «tiene el irrenunciable derecho de conocer la verdad sobre lo que ha ocurrido [...] con el propósito de evitar una repetición de hechos similares en el futuro» ${ }^{17}$. El Relator también recalcó como: «avanzar realmente hacia el futuro y continuar en el camino del desarrollo supone necesariamente que los derechos a la verdad, la justicia, la reparación y las garantías de no repetición sean cumplidos y eso es responsabilidad de los tres poderes que comprende el Estado» (de Greiff, 2014: 23). Por cuanto pueda parecer obvio, el Estado en su totalidad tiene que dedicarse al esfuerzo de reparar los crímenes que el mismo estado cometió. Especialmente el proceso judicial no ha contado, ni cuenta aun, con la colaboración del Estado en términos de recursos y acceso a la información y archivos. Como bien ha recalcado el Fiscal de Corte, Uruguay no tuvo una estrategia común en la persecución de los crímenes de la dictadura, perdiendo de tal manera mucho tiempo. Faltando una posición institucional, los avances que existieron dependieron de operadores particulares del sistema judicial que impulsaron las investigaciones, como la ex fiscal Mirtha Guianze o la jueza Mariana Mota, entre otros ${ }^{18}$.

41 A 30 años del retorno de la democracia en Uruguay y 40 años de la fundación del Plan Cóndor - cuya víctimas fueron de hecho en su mayoría ciudadanos uruguayos exiliados por toda Suramérica- el gobierno uruguayo tiene que comprometerse una vez por todas con las tareas ya impostergables de trabajar por justicia, verdad, y reparación de los crímenes del terrorismo de Estado de su pasado reciente. 


\section{BIBLIOGRAFÍA}

BARAHONA DE BRITO Alexandra (1997), Human Rights and Democratization in Latin America: Uruguay and Chile, Oxford: Oxford University Press.

BURT Jo-Marie, FRIED Gabriela \& LESSA Francesca (2013), «La sociedad civil y el resurgir de la lucha contra la impunidad en Uruguay (1986-2012)», Artículo Primero, 1(1), 7-26.

CIDH (1992), Informe n. $.^{\circ} 28 / 92$, Casos 10.147, 10.181, 10.240, 10.262, 10.309 y 10.311. OEA/Ser.L/V/

II.83 Doc. 14: Comisión Interamericana de Derechos Humanos, 2 de octubre.

CONADEP (2006), Informe de la Comisión Nacional sobre la Desaparición de Personas - Nuncas Más, Buenos Aires: Editorial Universitaria de Buenos Aires.

CONTRERAS Mariana \& TOURIÑo Rosario (2011), «Escrito en el cuerpo. Tortura y violencia sexual en dictadura: la otra gran batalla política», Brecha, 4 de noviembre.

CRENZEL Emilio (2008), La historia política del Nunca Más. La memoria de las desapariciones en la Argentina, Buenos Aires: Siglo XXI Argentina.

Dinges John (2004), The Condor Years: How Pinochet and His Allies Brought Terrorism to Three Continents, New York, London: New Press.

FRIED Gabriela \& LESSA Francesca (eds.) (2011), Luchas contra la impunidad: Uruguay 1985-2011, Montevideo: Trilce.

GREIFF Pablo DE (2014), Informe del Relator Especial sobre la promoción de la verdad, la justicia, la reparación y las garantías de no repetición. Consejo de Derechos Humanos, $27^{\circ}$ período de sesiones, 28 de agosto de 2014, A/HRC/27/56/Add.2.

IACHR (1992), Report No. 29/92 - Uruguay. Inter-American Commission on Human Rights, < www.cidh.org/annualrep/92eng/Uruguay10.029.htm>.

IACtHR (2011), Case Gelman vs Uruguay. Merits and Reparations. Judgment of February 24, 2011. Series C No. 221.

LESSA Francesca (2014), ¿Justicia o impunidad? Cuentas pendientes en el Uruguay post-dictadura, Montevideo: Penguin Random House.

LESSA Francesca \& LE GoFF Pierre-Louis (2013), «Uruguay's Culture of Impunity Continues to Rear its Head», Al Jazeera, <www.aljazeera.com/indepth/opinion/2013/02/2013219105659440890.html $>$.

LIRA Elizabeth (2011), «Chile: Verdad, Reparación y Justicia: el pasado que sigue vivo en el presente», in Instituto Interamericano de Derechos Humanos (ed.), Contribución de las políticas de verdad, justicia y reparación a las democracias en América Latina, San José, Costa Rica: Instituto Interamericano de Derechos Humanos, 85-128.

MARCHESI Aldo (ed.) (2013), Ley de Caducidad. Un tema inconcluso, Montevideo: Trilce.

MCSHERRY J. Patrice (2005), Predatory States: Operation Condor and Covert War in Latin America, Lanham (MD), Oxford: Rowman \& Littlefield Publishers, Inc.

RODRíGuEz Roger (2011), «La legitimidad caducada», Caras \& Caretas, 1 de julio. 
SIKKINK Kathryn (2008), «From Pariah State to Global Protagonist: Argentina and the Struggle for International Human Rights», Latin American Politics and Society, 50(1): 1-29.

\section{NOTAS}

1. Ver < www.fiscales.gob.ar/lesa-humanidad/wp-content/uploads/sites/4/2015/11/InformeLesa-final.pdf>.

2. Ver <www.ddhh.gov.cl/n122_10-12-2015.html>.

3. Entrevista con Mirtha Guianze, 4 de abril de 2014.

4. Correo electrónico de Pablo Chargoñia a la autora, 19 de enero de 2014.

5. Ver <www.observatorioluzibarburu.org/reportes/>.

6. Email de Pablo Chargoñia a la autora, 15 de julio de 2015.

7. Ver «Organizaciones de DDHH advierten "estancamiento" en los procesos de justicia», in De Diez a Doce, Radio Uruguay, 10 de noviembre de 2015, <www.radiouruguay.com.uy/innovaportal/ $\mathrm{v} / 78411 / 22 /$ mecweb/organizaciones-de-ddhh-advierten-estancamiento-en-los-procesos-dejusticia?parentid=62683>.

8. Causas 87-130/2012 (<www.observatorioluzibarburu.org/causas/1>) y 97-78/2012 (< www.observatorioluzibarburu.org/causas/123>).

9. Ver < www.fiscalia.gub.uy/innovaportal/v/75029/52/mecweb/fiscal-de-corte-crea-unidadespecializada-en-derechos-humanos?parentid=64689>.

10. Entrevista a la Dr. ${ }^{a}$ Pilar Elhordoy Arregui, 11 de septiembre de 2007.

11. Presentación de la Prof. Carla Larrobla, Facultad de Humanidades y Ciencias de la Educación de la UDELAR, en el Coloquio Mémoire, vérité et justice en Uruguay en Grenoble, Francia, 10 de octubre de 2014.

12. «Poder Ejecutivo crea por decreto grupo de trabajo por Verdad y Justicia para investigar crímenes de lesa humanidad», La República, 20 de mayo de 2015, <www.lr21.com.uy/ politica/1233738-poder-ejecutivo-grupo-verdad-justicia-crimenes-dictadura>.

13. Ver Capítulos VI y VII de la Ley de Amnistía N. ${ }^{\circ}$ 15.737. Disponible en <https://www.icrc.org/ ihl-nat.nsf/a24d1cf3344e99934125673e00508142/ca3a4ca11b4d5710c125705400467bee/\$FILE/LEY \%20DE\%20AMNISTIA.pdf>.

14. Pacto Internacional de Derechos Civiles y Políticos. Disponible en < www.ohchr.org/SP/ Professionalinterest/Pages/CCPR.aspx>.

15. Caso Radilla Pacheco vs. México. Excepciones Preliminares, Fondo, Reparaciones y Costas. Sentencia de 23 de noviembre de 2009. Serie C N. ${ }^{\circ}$ 209, párr. 166. Ver también Caso Trujillo Oroza vs. Bolivia. Reparaciones y Costas. Sentencia de 27 de febrero de 2002. Serie C N. ${ }^{\circ}$ 92, párr. 114; Caso La Cantuta vs. Perú, Fondo, Reparaciones y Costas. Sentencia de 29 de noviembre de 2006 . Serie C N. ${ }^{\circ} 162$, párr. 125.

16. Caso Radilla Pacheco vs. México. Excepciones Preliminares, Fondo, Reparaciones y Costas, párr. 167. Ver también Caso Blake vs. Guatemala, Fondo. Sentencia de 24 de enero de 1998 . Serie C N. ${ }^{\circ} 36$, párr. 114.

17. Informe N. ${ }^{\circ} 136 / 99$, Caso 10.488, El Salvador, 22 de diciembre de 1999, párr. 226, < www.cidh.org/annualrep/99span/De\%20Fondo/El\%20Salvador10.488.htm>.

18. Ver «Díaz: Fiscalía General va hacia estrategia unificada para casos de crímenes de la dictadura», in De Diez a Doce, Radio Uruguay, 23 de noviembre de 2015, <www.mec.gub.uy/ innovaportal/v/79002/22/mecweb/diaz:-fiscalia-general-va-hacia-estrategia-unificada-paracasos-de-crimenes-de-la-dictadura?parentid=11305>. 


\section{RESÚMENES}

Este artículo analiza la trayectoria de Uruguay en los últimos 30 años, desde el retorno a la democracia hacia el presente, haciendo un balance de los avances y de los desafíos pendientes en la lucha por verdad y justicia por los crímenes de la dictadura de 1973 a 1985. En particular, subrayaré las tareas que quedan irresueltas y por tanto las que el nuevo gobierno que asumió en marzo de 2015 habrá de encargarse. El análisis se divide en dos partes. En primer lugar, se inserta el caso uruguayo en el marco regional del Cono Sur, comparándolo brevemente con las trayectorias de la lucha por verdad y justicia en Argentina y Chile. En la segunda parte, e inspirada en el informe sobre Uruguay presentado en setiembre de 2014 al Consejo de Derechos Humanos de las Naciones Unidas por el Relator Especial sobre la promoción de la verdad, la justicia, la reparación y las garantías de no repetición, Pablo de Greiff, la discusión se organizará en torno a cuatro ejes principales: justicia, verdad, memoria y reparación. A más de 40 años de los hechos, es absolutamente urgente que el Estado uruguayo actúe sin más demoras en proporcionar respuestas ya largamente esperadas a los familiares de las víctimas, los sobrevivientes y la sociedad en general, sobre los crímenes que se cometieron durante la dictadura.

This article discusses Uruguay's transitional justice trajectory over the past 30 years, from the time of the return to democracy till present; it evaluates both the progress made so far and the remaining challenges ahead in the search for truth and justice regarding the crimes of the dictatorship (1973-1985). In particular, the article highlights pending questions that the new Government, which took office in March 2015, will need to address in the near future. The analysis is divided into two parts. First, the Uruguayan case is analysed within the comparative regional framework of the Southern Cone, briefly considering the struggle for truth and justice in neighbouring Argentina and Chile. Second, and following the format of the report about Uruguay presented in September of 2014 to United Nations Human Rights Council by the Special Rapporteur on the promotion of the truth, justice, reparation and guarantees of non-recurrence, Pablo de Greiff, the discussion is organized around four main axes: justice, truth, memory and reparation. Forty years after the crimes of the dictatorship, Uruguay must act without any further undue delay to deliver long-awaited answers to victims' relatives, survivors and society as a whole.

Cet article analyse la trajectoire de l'Uruguay dans les trente dernières années, depuis le retour à la démocratie jusqu'à ce jour, en faisant un bilan des avancées et des questions en suspens de la lutte pour la vérité et la justice par rapport aux crimes de la dictature. Seront particulièrement soulignés les problèmes non résolus et donc, les tâches qui incombent au nouveau gouvernement en place depuis mars 2015. L'analyse peut être divisée en deux parties. En premier lieu, le cas uruguayen est inséré dans le cadre régional du Cône Sud, la trajectoire nationale de lutte pour la vérité et la justice étant brièvement comparée à celles de l'Argentine et du Chili. Dans la deuxième partie, inspirée du rapport sur l'Uruguay présenté en septembre 2014 au Conseil des droits de l'homme de l'ONU par le Rapporteur spécial sur la promotion de la vérité, de la justice, de la réparation et des garanties, Pablo de Greiff, la discussion s'organisera autour de quatre axes principaux : justice, vérité, mémoire et réparation. 40 ans après les faits, il est absolument urgent 
que l'État uruguayen agisse sans plus attendre en vue de donner des réponses trop longtemps attendues aux familles de victimes, aux survivants et à la société en général, sur les crimes commis en dictature.

ÍNDICE

Palabras claves: Uruguay, Argentina, Chile, justicia transicional, impunidad, verdad, justicia, reparación, memoria

Keywords: Uruguay, Argentina, Chile, transitional justice, impunity, truth, justice, reparation, memory

Mots-clés: Uruguay, Argentine, Chili, justice transitionnelle, impunité, vérité, justice, réparation, mémoire

\section{AUTOR}

\section{FRANCESCA LESSA}

Latin American Centre, University of Oxford.

Dr. ${ }^{a}$ Investigadora en el Centro Latinoamericano de la Universidad de Oxford. Consultora internacional del Observatorio Luz Ibarburu. Es autora del libro iJusticia o impunidad? Cuentas pendientes en el Uruguay post-dictadura, Montevideo: Penguin Random House, 2014. 